\title{
COMO O DESIGN-THINKING CONTRIBUI PARA A GESTÃO ESTRATÉGICA
}

\author{
Por Marcos Mueller Schlemm ${ }^{1}$
}

Entrevista realizada com Richard Buchanan (RB) por Marcos M. Schlemm (MS), na sede da Weatherhead School of Management da Case Western Reserve University, em Cleveland, Ohio, no dia 14 de setembro de 2010, por ocasião de workshop conduzido para professores da Universidade Federal do Paraná e técnicos do Sesi-PR.

Richard Buchanan, PhD pela Chicago University, é professor de Design, Gestão e Sistemas de Informação da Weatherhead School of Management na Case Western Reserve University. Foi diretor e professor da School of Design na Carnegie Mellon University. Lecionou em áreas tradicionais do design gráfico e industrial, bem como na emergente área de design de interação. Atualmente é conhecido por estender a metodologia de design-thinking para outras áreas de pesquisa e aplicação, incluindo interações coletivas humanas, mídia social, gestão, design organizacional e ambientes sistêmicos. Ministra cursos e palestras em diversas regiões nos Estados Unidos e em mais de 40 países na Europa, Ásia, América do Sul, África e Oceania. É coeditor do Design Issues, periódico internacional publicado pela MIT Press e escreveu os seguintes livros: Discovering Design: explorations in design studies, The idea of design e Pluralism in theory and practice.

MS: Agradeço em nome da revista Rebrae a oportunidade desta entrevista.

RB - Fico contente em conversar com você sobre este tema muito atual e relevante para o desenvolvimento da teoria e prática da gestão e da estratégia empresarial. Tenho muito respeito pelo que é feito no Brasil pela comunidade do design, assim como na administração dos novos empreendimentos.

MS: Talvez seja interessante iniciar com a proposição do design como modo de pensar a gestão e a prática resultante ou, como vocês aqui na Weatherhead School of Management estão sugerindo, managing as designing (administrando como se estivéssemos desenhando).

$\mathbf{R B}$ - Este é um tópico muito discutido neste momento nas escolas de gestão e acredito que dentro da comunidade do design também. Como conseguir o alinhamento entre estas duas comunidades, do design e da gestão? Acredito que o modo de pensar do design (design-thinking) oferece muitas

\footnotetext{
1 Administrador, prof. Dr. de Pós-Graduação em Administração da Pontifícia Universidade Católica do Paraná (PUCPR), assessor executivo da presidência da Federação das Indústrias do Paraná (FIEP), Curitiba, PR - Brasil, e-mail: marcos.schlemm@fieppr.org.br
} 
possibilidades para o crescimento e desenvolvimento de novas formas de pensar e enfrentar as novas situações que estamos vivendo hoje em dia.

MS: Como o senhor chegou a esta forma de conceber e solucionar questões organizacionais?

RB - Tenho uma formação em design e fui diretor da Escola de Design na Carnegie Mellon University. Lá existe o programa de design industrial e design na comunicação, o qual levou à estruturação do programa de design de interações (interaction design), do qual tenho muito orgulho. Penso que foi o primeiro no mundo com esta proposta. Neste momento pesquiso como as interações humanas se desdobram no design de serviços. Considero esse foco muito relevante, com avanços significativos numa economia em que a participação dos serviços é crescente. Isso é verdade, não somente nesta sociedade. Economias em desenvolvimento também estão tendo uma participação crescente dos serviços na concepção dos produtos. As economias estão se transformando em sociedades de serviços. De fato, é difícil hoje em dia pensar num produto que não tenha algum tipo de serviço em torno dele. Se você for comprar algum equipamento eletrônico hoje em dia, você vai constatar que existe um conjunto de serviços em torno dele que constituem uma parte significativa deste produto. Você adquire uma inteira conexão com a empresa. Eu vejo que isso muda não apenas a interação com o artefato em si, muda também a nossa relação com as empresas.

MS: O senhor poderia elaborar um pouco mais esta noção?

RB - Tendemos a pensar sobre organizações como se fossem constituídas apenas pelas fronteiras representadas pelos seus assalariados ou pelas pessoas que detêm ações destas organizações. Mas acredito que nesta nova forma como os produtos e serviços estão sendo vistos, acabamos por constatar que as fronteiras das organizações são muito diferentes daquelas que costumávamos imaginar. Que, de fato, os clientes e as pessoas aos quais servimos, de alguma forma, já fazem parte da organização. Isso é um assunto muito sério. Existe um artigo maravilhoso do Philip Kottler com o título: "Humanistic Marketing". Neste artigo ele coloca quatro formas de relacionamento de empresas com seus clientes. A quarta e mais avançada forma de empresa é aquela em que o cliente está dentro da organização e não fora dela. Vejo isso como um desenvolvimento importante no entendimento de como funcionam as organizações. E é esta a ideia do design. Porque uma das questões essenciais no design é a preocupação com os seres humanos, a empatia pelos usuários, assim como o interesse pela comercialização. Estas duas coisas juntas. Assim, no design começamos com a experiência do cliente e seguimos construindo o produto para dentro da organização. Geralmente os negócios não são feitos desta forma. Tipicamente a empresa desenvolve um produto e considera o cliente como um felizardo que decidiu comprá-lo. Mas você sabe que o mundo está ficando cada vez mais competitivo, o que requer uma mudança na atitude por parte das empresas. Requer o reconhecimento das realidades dos relacionamentos existentes. Isso traz consequências para o propósito das organizações. Por mais de quatro décadas estivemos obcecados com a noção de lucro num sentido muito estreito.

\section{MS: Qual seria o novo sentido do lucro nesta perspectiva?}

RB - Acredito que temos que reconhecer que lucro não é apenas uma questão financeira, mas que se constitui no serviço e no beneficio que trazemos às pessoas que adquirem nossos produtos. Esta é uma ideia que nos remete às proposições do Chester Barnard nas décadas de 1930 e 40, no seu grande insight sobre o propósito das organizações: servir o cliente. O lucro não é para ser de forma alguma desconsiderado, continua sendo um aspecto crucial. Lucro é uma forma de medirmos nosso sucesso, ele proporciona os recursos para investimento em bens de capital e para o desenvolvimento de novos produtos. 
MS: Quando introduzimos o conceito de design e do design-thinking no âmbito da gestão estratégica, a primeira reação das pessoas é buscar sua referência no conceito histórico do design, comumente associado à forma das coisas. Como novo campo de estudo, entendemos que não lidamos com uma simples questão semântica; há algo a ser superado para que este novo entendimento seja assimilado e propagado na comunidade acadêmica e no mundo corporativo.

RB - Acredito que você está certo. Penso que a palavra "design" traz uma bagagem consigo. Não é uma bagagem ruim, é boa, graças ao grande trabalho realizado pelo design nos séculos passados. Porém, traz os significados dos primórdios do design. Em minha própria carreira eu procurei cruzar diferentes áreas de aplicação do design. Isso me levou a formular o que intitulo os quatro níveis do design. São os quatro grandes problemas com os quais designers se defrontam no seu trabalho. E é verdade: nos primeiros momentos do século passado estivemos envolvidos com os aspectos gráficos e de comunicação do design, o foco era o design industrial e a produção de artefatos. Estes mudaram organizações e de fato tiveram grandes impactos sociais. Mas hoje estamos indo em direção ao que chamo de terceiro e quarto níveis do design. Não estamos interessados no que comumente chamamos de posters e toasters. Estamos interessados em saber como desenhamos ações, processos e interações, em como desenhamos os ambientes e os sistemas nos quais estas interações devem acontecer. Com isso nós descobrimos duas novas aplicações para o design. E elas trazem consigo a importância do design da comunicação, do design de artefatos, do design industrial, mas nos incitam a considerar a importância da interação com as pessoas, e isso nos leva aos serviços. Traz a consciência de que podemos conceber. $\mathrm{Na}$ Escola de Design da Carnegie Mellow eu lidava com os aspectos do design enquanto comunicação, com design industrial e com interações individuais. Como uma pessoa interage, por exemplo, com um computador ou uma máquina. Aqui na Weatherhead School of Management começamos a pesquisar a interação das pessoas de outras formas. Nós nos afastamos do mundo plano do computador ou da tela do computador, do painel de controle e da superfície do aparelho. Começamos a dizer que estes artefatos pedem por interações mais profundas. Será que somos capazes de desenhar estas interações? Isso me conduziu das interações individuais para o que chamo de interações coletivas. O desenho de interações coletivas.

MS: Isso parece trazer uma reflexão sutil e interessante para a questão de como vemos organizações.

RB - Eu tenho uma teoria sobre organizações. Eu creio que organizações são coleções de interações, muitos tipos de interações. Mas são as interações humanas que constituem verdadeiramente as organizações. Agora, é verdade que organizações são constituídas para atender propósitos, mas são as interações que servem a estes propósitos. São as interações que dão suporte à divisão do trabalho. Talvez possamos ver isso de outra forma. Eu acredito que nós, seres humanos, não temos a capacidade de ter a experiência de um sistema, por definição, um ser humano não pode vivenciar um sistema. E esta é uma perspectiva bem controversa, eu sei. Mas minha noção do que constitui um sistema me leva a esta conclusão. Um sistema é tudo o que aconteceu no passado, tudo o que está acontecendo agora e tudo o que irá acontecer no futuro. E somente Deus pode ter toda esta experiência. Para mim e para você, nós seguimos a nossa própria experiência ao longo de nosso caminho pessoal. O sistema solar? Sim, nós temos uma teoria sobre ele. Podemos representá-lo com diagramas e fórmulas e assim por diante. Mas a verdade é que, ao cabo de tudo, eu sei quantos ciclos do sol eu experimentei em minha existência. Minha filha tem 21 ciclos. Eu tenho alguns mais, mas é isso.

MS: Que implicação tem esta noção para o design cotidiano a ponto de ser objeto de atenção das pesquisas em como as organizações deveriam proceder?

RB - Acredito ser um assunto muito significativo. Sugere que devemos iniciar o design a partir da experiência pessoal e adentrar a complexidade das organizações em direção ao topo. Iniciamos com a 
experiência do usuário ou cliente e construímos para servir àquele indivíduo. Este entendimento para mim é coerente com o que importantes teóricos da economia já afirmaram. Eu certamente tenho muito respeito pelo trabalho do Frank Knight, grande economista, e por Schumpeter e sua noção da destruição criativa. Tenho interesse no trabalho de outros economistas que perceberam que organizações são parte de um processo social. Por isso, minha referência anterior sobre qual o propósito das organizações. Bem, e para ser coerente com esta visão, o lucro deve ser visto num sentido mais amplo.

MS: Este entendimento certamente pede por outras considerações na formulação estratégica das organizações.

$\mathbf{R B}$ - Este é o ponto no qual estratégia assume significado especial para mim. E serei bem cuidadoso quanto ao que vou dizer, porque existe uma tendência de fundir visão com estratégia na mesma conversa - e acredito que isso é um erro. Mintzberg apresentou um argumento poderoso sobre a ascensão e a queda do planejamento estratégico. Em seu livro, ele argumenta contra a elaboração da visão por parte de estrategistas. Visão é algo que pertence aos líderes e às organizações. E são da sua responsabilidade o desenvolvimento e a articulação da visão de uma organização ou empreendimento. Quando esta visão é compreendida e os valores e propósitos são identificados, aí sim podemos falar da estratégia, de como os recursos serão utilizados num ambiente competitivo e, de fato, de como elaboramos uma estratégia de design. Mas design entrou nessa conversa de uma forma muito surpreendente. Existe um livro recente muito interessante intitulado The lords of strategy, que recomendo a todos aqueles que querem entender o crescimento da estratégia como preocupação dos negócios. É o estudo das grandes empresas de consultoria, Bain, Boston Consulting Group, McKinsey e também de alguns acadêmicos, particularmente Michael Porter e seu papel nesta questão.

MS: Qual o aspecto central ilustrado neste livro?

RB - O livro é bem interessante porque ele chama a atenção para o fato de que a estratégia no passado nos conduziu para uma discussão e foco sobre custos e redução de custos. Neste livro, o problema que nos assombra e se faz presente é como vamos trazer a estratégia para dentro das organizações, como, afinal, implementar esta estratégia, como executar.

MS: Que implicações estas questões têm para a nossa conversa aqui?

RB - Sinceramente sei de um grande número de empresas de consultoria que estão bem ansiosas para contratar designers agora porque estão se dando conta de que tem algo faltando na discussão sobre estratégia. Algo ainda está faltando. Por mais poderosas que as ferramentas e conceitos vindos da estratégia possam ser, revelando o posicionamento competitivo e a análise das forças e fraquezas, ainda existe algo faltando. E eu te digo, eu acredito que o que está faltando é design. Design para trazer a estratégia para o cotidiano das organizações. Para dar vida. Então, eu não delegaria aos estrategistas e consultores externos esta tarefa. Acredito que o design diz: "Vamos dar uma olhada no nosso cliente, nosso consumidor, o usuário do nosso produto ou serviço, que, afinal, é o beneficiário de tudo o que fazemos. E vamos olhar dentro da sua experiência e entender como nosso produto/serviço produz valor e significado para ele". Não é olhar para descobrir como cortar custos. É sobre uma nova forma de empreender. Para mim, empreendedorismo é a palavra equivalente ao design nos negócios.

MS: Empreendedorismo tem sua bagagem de interpretações e conceitos também.

RB - É verdade. De forma equivocada, algumas pessoas pensam que empreendedorismo se restringe a iniciar pequenos negócios. Esta é uma pequena parte do significado de empreendedorismo. Eu acredito que Peter Drucker nos dá a melhor definição de empreendedorismo. Ele escreveu um livro 
muito importante que deu início à discussão de empreendedorismo na comunidade de negócios. Nele Drucker argumenta que empreendedor é um hábito. Um hábito mental. Não é um traço de personalidade, não é temperamento, não é o DNA. Toda esta linha de pesquisa é frívola. Empreendedorismo é um hábito, é isto. Empreendedorismo é um hábito de inventar novas ideias e de desenvolver estas ideias para transformá-las em inovações que beneficiam organizações e as pessoas servidas por estas organizações. Inventar ideias e desenvolvê-las em inovações. Drucker deixou claro que empreendedorismo não se refere apenas a pequenos negócios. Empreendedorismo é o que faz pulsar novas ideias em organizações já existentes de grande porte. Em qualquer lugar onde indivíduos têm novas ideias e as transformam em inovações, eles estão sendo empreendedores. Drucker estabeleceu as conexões com o que ele chamou de a sociedade empreendedora. Como em muitos outros temas, ele foi presciente. Ele tinha uma forma de ver o futuro. Nós estamos num período em que precisamos de forma dramática de uma sociedade empreendedora. Um mundo de crescente complexidade, conflitos difíceis, divergência nos valores, que requer muito empreendedorismo. Novas ideias e inovação.

MS: Drucker pode ser visto então como um precursor nesta discussão?

RB - O que sinto falta em Drucker e com os autores em estratégia é o conceito de design. Drucker para bem às portas do design. Ele para no limite de capturar o conceito para dentro da sua visão. Ele está certo quando fala que empreender é um hábito, um modo de trabalhar, e neste sentido todas as disciplinas são hábitos. Mas Drucker não sabia que existe uma disciplina que faz exatamente o que ele sugere na atividade empreendedora. Tal disciplina é design. Então, a ideia de inventar ideias e desenvolver inovações que beneficiam pessoas é uma das melhores definições que já vi acerca do design. Existem definições formais, definições acadêmicas e outras de profundidade teórica que são boas, mas esta é uma definição prática muito boa. Acredito que se Drucker fosse vivo hoje, diria que design é nossa forma de promover o avanço.

MS: Como foi o seu envolvimento com esta visão de empreendedorismo e design?

RB - É com ela que minha carreira tomou forma aqui na Weatherhead School of Management. Não abandonei o design, mas eu o pratico agora no terceiro e quarto níveis. Níveis de ação e interações; interações coletivas. Estou procurando compartilhar as técnicas e conceitos de design que são tão poderosas em outras formas em que o design é praticado e trazê-las para este novo ambiente. Porque, francamente, o termo inovação para mim é muito vago. Empreendedorismo tem também uma bagagem. E assim também o design. Por isso me agrada falar de design entrepreneurship como uma frase que define managing as designing. Acredito que é isto o que estamos construindo aqui. Esta é forma como elaboramos nossas estratégias e as executamos, implementamos e avaliamos.

MS: O senhor poderia comentar um pouco mais sobre estas ferramentas e técnicas do design?

RB - Existem técnicas específicas, métodos para trabalhar conforme a abordagem do design. Vimos algumas aqui neste workshop, mas existem outras. Invenções são para mim uma atividade disciplinada. A teoria da invenção é muito interessante. Gostaria de ter tido mais tempo para explorar a teoria das invenções (invention theory). Estas são algumas das ideias e formas de praticar design.

MS: Se pensarmos na comunidade envolvida com pesquisa nos negócios que têm como agenda o tema da estratégia empresarial, como o senhor vê a questão do design nesta agenda? No Brasil, a noção de estratégia cresceu a partir de autores principalmente americanos e agora temos esta questão do design-thinking despontando em algumas das principais escolas de negócio e centros de pesquisa. Alguns têm associado o conceito da estratégia ao design como substituto do design-thinking. Como o senhor vê estas questões? 
RB - Esta é realmente uma questão importante, a noção da pesquisa em estratégia, gestão e agora em design. Eu fui presidente da Design Research Society, uma organização internacional dedicada aos estudos e pesquisas interdisciplinares sobre a natureza do design. Uma coisa que quero destacar é que design preocupa-se com produzir, com fazer. Nossas comunidades de pesquisa geralmente se concentram no desenvolvimento de teorias e práticas, mas têm pouco entendimento sobre o que é necessário para fazer algo. Teoria, prática e produção, estas são as três grandes questões que importam. Nossas universidades são especializadas em teoria. Elas toleram prática. Hoje em dia elas têm que tolerar isso na Medicina, Direito e Administração. Mas ainda temos uma grande dificuldade em botar nossas mãos em torno da noção do fazer. E eu penso que se estamos procurando impactar a forma como vivemos nossas vidas, sobre o mundo à nossa volta, nós temos que encarar a importância do fazer. Transformar o fazer no objeto de pesquisa, de investigação. Então sou bastante cauteloso nesta questão, mas surpreendentemente tenho visto poucas pesquisas sobre os processos, as atividades e práticas do designing. Qual ideia chega a algum resultado? Qual não? E por quê?

MS: Na sua observação do que está sendo feito em termos de pesquisa no âmbito da administração dos negócios, qual tem sido a orientação destes estudos?

RB - Pesquisa no âmbito das escolas de negócio tende a focar aquilo que já foi desenhado. Discutimos as organizações como elas são, sua história e suas práticas. Mas há pouco foco sobre a prática do design, como se o trabalho efetivo de conseguir fazer algo não tivesse importância.

MS: Retomando então o assunto da agenda de pesquisa nesta frente...

RB - Sim, o que seria uma agenda avançada nesta questão. Preocupa-me o termo design-estratégico. O que significa isso? Desenhar uma estratégia? Não acredito ser um termo muito útil para o que tentamos fazer. Estou mais interessado em entender como usamos o design para dar forma às organizações. Vamos simplificar. Existe uma tendência muito forte na comunidade empresarial para encontrar uma frase rápida, e matamos tantas boas ideias ao rotular e as utilizar à exaustão. Sou meio duro em relação a isso com a comunidade empresarial. Eu venho de uma área diferente da academia. Sou um pouco mais cético quanto à urgência de dar nomes a algo. Como se, ao nomear algo, pudéssemos guardar na prateleira, mas não quero ser evasivo nisso. Existem questões importantes a serem investigadas. Queremos saber como a inovação ocorre, queremos estudar as questões do design. Que conceitos e métodos do design podem ser trazidos para a vida das organizações? Quais práticas do design?

MS: Com as crescentes turbulências globais, a questão da sustentabilidade e da complexidade dos sistemas, nosso conhecimento e capacidade de lidar de forma efetiva com estas questões multidimensionais parecem insuficientes e pedem por algo mais adequado. O design seria este novo conhecimento ou forma de abordar e solucionar os problemas que se apresentam dia a dia com maior frequência e intensidade?

RB - Existe uma possibilidade neste sentido. Há espaço para isso. Existe uma razão para o design oferecer uma forma de se avançar nisso. Eu seria cauteloso e humilde neste estágio. Eu penso sobre o que define um produto. E, por favor, entenda que em séculos anteriores um produto era um artefato. No início do século XXI um produto é qualquer coisa criada por humanos (sistemas, arquitetura da informação, conceitos, etc.). Entendo que um produto deve possuir três características centrais: a) utilidade: deve possuir uma lógica (razão tecnológica) que permita o produto ser útil. Esta condição não faz um produto, é uma parte do produto. Engenheiros imaginam que eles desenham produtos com esta definição como suficiente; b) usabilidade: deve servir à mente e às mãos da pessoa que irá utilizar o produto. O produto não é bom se o seu acesso for difícil ou muito caro. Um bom design dá acesso; c) desejável: se não encontramos algo com o qual nos identificamos, não temos vontade de levar para nossas vidas, nossas casas ou outro lugar, não será efetivo como produto. 
Mas pense sobre isso: qual a fonte do conhecimento para cada uma destas características? As engenharias e ciências técnicas contribuem para a utilidade do produto. Psicologia e outras ciências humanas contribuem para descobrir, permitem a usabilidade de um produto. A antropologia e novamente as demais ciências humanas auxiliam na compreensão do que torna algo desejável em nossas vidas.

\section{MS: Como o design entra neste processo?}

$\mathbf{R B}$ - O design integra estas três dimensões e estes conhecimentos encontrando um equilíbrio entre o que é útil, o que é fácil de usar, e o que é desejável. Estou querendo chegar ao argumento aqui de que design oferece a possibilidade de conseguir um avanço nestas questões complexas porque incorpora todos estes tipos de conhecimento de que precisamos para a integração. Design é uma disciplina integrativa. Ele busca as relações que são práticas e viáveis. Busca o uso apropriado do conhecimento técnico. Para mim, design oferece a possibilidade de solucionar problemas muito complexos. A propósito, eu considero estes problemas como sendo problemas de terceiro nível. $\mathrm{O}$ sistema no qual vivemos. $\mathrm{O}$ sistema natural e os sistemas humanos e como exploramos a relação entre estes dois sistemas. Design é sobre isso. Design não é uma palavra chavão. Sua bagagem e tradição valem a pena serem investigados.

\section{MS: Como o senhor define sua missão pessoal hoje na escola?}

RB - Eu diria que minha vinda para a Weatherhead School of Management fez com que eu buscasse dois objetivos principais no ensino da gestão. O primeiro é fazer meus alunos de MBA entenderem os produtos e serviços de suas companhias. Há um sentimento muito forte de que os estudantes de Administração ficaram muito abstratos e analíticos, alheios aos produtos e serviços reais. Considero este propósito importante. Mas meu segundo objetivo aqui é o que realmente me empolga. Como utilizar ideias do design para gerar inovação na forma como funcionam as organizações, como gerimos e lideramos as nossas organizações. Como criar organizações mais satisfatórias para os indivíduos e para servir melhor à sociedade.

MS: Esta noção que vem da Weatherhead, do managing as designing como algo que se contrapõe ao modelo da eficiência e análise, abrindo mais oportunidades para que ocorra a inovação, por ser mais inclusivo e aberto na forma de pensar as soluções, seria uma nova via para a gestão?

RB - Sim, acredito que a história das escolas de gestão e negócios é uma história de ensino de conceitos analíticos. Ensinam gerentes intermediários. As escolas querem produzir indivíduos analíticos. Poucas pessoas são educadas para sintetizar. Habilidades analíticas são importantes, não há nenhuma questão quanto a isso. Eu preciso saber lidar com dados e números, com conceitos contábeis, entender um balanço, mas estes não são suficientes para se equivaler a uma organização. Temos que ensinar gerentes a produzir sínteses. Como tomar os resultados analíticos e criar resultados rentáveis e sustentáveis. Creio que é esta a revolução que está ocorrendo nas escolas de gestão e de negócios. Reconhecer a importância dos instrumentos analíticos e das especializações profissionalizantes, mas ver também a gestão como uma forma mais elevada de trabalho. Aqui na Weatherhead temos uma frase que diz ser a gestão uma profissão nobre. Veja que frase interessante. Não sei se é arcaica ou presciente, olhando para o futuro. Qual a nobreza? Novamente encontramos em Drucker a resposta. Ele afirmou que "gestão não é uma ciência e também não é uma profissão, embora haja elementos de ambos". Eu refleti sobre o que ele quis dizer com isso e comecei a compreender o que seria seu sentido. Gestão se coloca acima das profissões, ela provê a conexão. Constitui-se no elemento de síntese que aglutina os elementos das profissões. Um administrador utiliza o conhecimento técnico, o científico e a prática profissional para produzir uma síntese maior. Acredito que é isso o que Drucker considera como administração. E é isso o que procuramos ensinar aqui e o que está começando a acontecer em outras escolas de administração também. 